\title{
Physical activity surveillance and emerging technologies
}

J. Aaron Hipp ${ }^{1}$

Rev Bras Ativ Fis Saúde p.2-4

DOI: http://dx.doi.org/10.12820/2317-

1634.2013v18n1p2

1 Brown School, Washington University in St. Louis, Prevention Research Center in St. Louis

Public health surveillance is the ongoing, systematic collection, analysis, and interpretation of outcome-specific data (e.g., physical activity) essential to the planning, implementation, and evaluation of public health programs, policies, and intervention. ${ }^{1}$ Two critical features of public health surveillance are that the system is active and ongoing, and that the function of surveillance is the expeditious dissemination of data. ${ }^{2}$ The consistent and up-to-date surveillance and evaluation of physical activity $(\mathrm{PA})$ in built environments $(\mathrm{BE})$ is critical for use in community to international obesity prevention evaluation. Recent work conducted at Washington University in St. Louis shows emerging technologies are able to facilitate both the active uptake and the timely dissemination of $\mathrm{PA}$ and $\mathrm{BE}$ data.

$\mathrm{PA}$ and $\mathrm{BE}$ research has experienced tremendous expansion during the past 20 years. ${ }^{3-5}$ The research has followed traditional patterns of growth beginning with ecological studies of association, ${ }^{6}$ then local validation of associations via retrospective surveys and researcher-present observation. ${ }^{7-10}$ Presently, natural experiments related to PA patterns and BEs are growing in popularity. ${ }^{11}$ These studies have been of great benefit to the field by informing public health and urban design. While there is now a substantial body of evidence to inform local interventions and policies, ${ }^{4,12-17}$ currently used methodologies and the use of small, local samples limit the PA surveillance, external validity, and dissemination of many results, interventions, and policies. There is a need for large-scale, evidence-informed surveillance of PA to increase the external validity of programs, policies, and BE change. ${ }^{18,19}$

Emerging technologies are now able to capitalize on the ubiquity and heterogeneity of data sources as well as employ crowdsourcing to evaluate and manage large datasets in an effort to increase public health surveillance. As an example, colleagues and I have recently embarked on a series of studies to validate the use of over 23,000 outdoor, publically-available on the Internet, webcams. The Archive of Many Outdoor Scenes (AMOS; http://amos.cse.wustl.edu) is a Washington University project which aims to capture and archive images from every publically-available, online, outdoor webcam (e.g., traffic cams, campus cams, ski-resort cams, etc.). This capture is archival, systematic, searchable, and ongoing, with images archived on average every thirty minutes (over 500 new images each minute). These webcams are capturing a wide array of $\mathrm{PA}$ patterns and $\mathrm{BE}$ characteristics and AMOS is very much an international dataset with over 9,000 non-US webcams, including at least 125 from Brazil.

We have been working to demonstrate and evaluate the potential for the AMOS dataset, and additional new outdoor webcams, to be re-purposed as a surveillance tool to evaluate patterns of human PA behavior in the urban BE. ${ }^{20}$ Our recent study annotated, or counted, the number of pedestrians, bicyclists, and vehicles present in photographs from one webcam, and found measurable changes in PA patterns after BE change (addition of a bicycle lane and new crosswalks). Work presented at the recent Active Living Research Conference (San Diego, CA; February 2013) included additional cameras and initial reliability and vali- 
dation efforts. ${ }^{21}$ Change in PA patterns appears to be associated with the amount and quality of $\mathrm{BE}$ change. With the ongoing capture of webcam scenes we can continue to track these trends and evaluate PA patterns across seasons, weather, and policy and $\mathrm{BE}$ change.

Due to the size of the AMOS dataset, we have used crowdsourcing to help annotate, or evaluate the captured scenes. Crowdsourcing refers to and utilizes the masses, or crowds, of individuals using the Internet, social media, and social mobile phone applications. The crowds participating in these websites and applications are the source of data or the source of needed labor. ${ }^{22}$ Crowdsourcing data collection in public health is an emerging field, with examples including the collection of tweets and Google searches that detected an increase in influenza before the increase in subsequent influenza-related hospital visits. ${ }^{22,23}$ Another potential use of crowdsourcing is as the labor in evaluation or assessment of research hypotheses. ${ }^{24-26} \mathrm{We}$ were the first to publish on the use of crowdsourcing (Amazon Mechanical Turk; www.mturk.com) as PA evaluators and surveillance.

This example of using emerging technologies in PA surveillance is novel in: (1) Its use of an international dataset of publically-available, online, outdoor webcams to capture PA patterns and BE characteristics; (2) Its ability to utilize crowdsourcing to reliably annotate captured images; and (3) Its capacity to be an ongoing, systematic PA surveillance system. The work also offers an innovative, transdisciplinary collaboration between computer science and public health.

Because AMOS captures photos of outdoor scenes from over 23,000 webcams, there is the opportunity to aggregate findings across a diverse sample of BEs and cities and generalize results of PA patterns and BEs. The opportunity offered by the unobtrusive webcams will provide an unbiased sample of human PA patterns within captured scenes, including scenes that have experienced policy, programmatic, and BE change during the ongoing (since 2006) automatic collection of scenes. The ultimate goal of our current PA and computer vision collaboration is to develop computer algorithms that will automatically identify and calculate PA patterns in webcam scenes, removing the current necessity of crowdsourcing annotation. This would be the ultimate in international PA surveillance.

\section{REFERENCES}

1. Teutsch SM, Thacker SB. Planning a public health surveillance system. Epidemiological Bulletin. 1995;16(1).

2. Thacker SB, Berkelman RL. Public health surveillance in the United States. Epidemiol Rev. 1988;10:164-190.

3. Rydin Y, Bleahu A, Davies M, et al. Shaping cities for health: complexity and the planning of urban environments in the 21st century. The Lancet. 2012;379(9831):2079-2108.

4. O. Ferdinand A, Sen B, Rahurkar S, Engler S, Menachemi N. The Relationship Between Built Environments and Physical Activity: A Systematic Review. American Journal of Public Health. 2012/10/01 2012;102(10):e7-e13.

5. Handy S, Boarnet M, Ewing R, Killingsworth R. How the built environment affects physical activity: views from urban planning. Am J Prev Med. 2002;23:64 - 73.

6. Ewing R, Schmid T, Killingsworth R, Zlot A, Raudenbush S. Relationship Between Urban Sprawl and Physical Activity, Obesity, and Morbidity. American Journal of Health Promotion. 2003/09/01 2003;18(1):47-57.

7. Parra DC, McKenzie TL, Ribeiro IC, et al. Assessing Physical Activity in Public Parks in Brazil Using Systematic Observation. Am J Public Health. June 17, 2010 2010:AJPH.2009.181230.

8. Reis RS, Hino AAF, Parra DC, Hallal PC, Brownson RC. Bicycling and Walking for Transportation in Three Brazilian Cities. American Journal of Preventive Medicine. 2013;44(2):e9-e17. 
9. McKenzie T, Cohen DA, Sehgal A, Williamson S, Golinelli D. System for Observing Play and Recreation in Communities (SOPARC): Reliability and feasibility measures. Journal of Physical Activity and Health. 2006;3(S1):S208-S222.

10. Bedimo-Rung AL, Gustat J, Tompkins BJ, Rice J, Thomson J. Development of a direct observation instrument to measure environmental characteristics of parks for physical activity. Journal of Physical Activity and Health. February, 2006 2006;3(Suppl 1).

11. Cohen DA, Marsh T, Williamson S, Golinelli D, McKenzie TL. Impact and cost-effectiveness of family Fitness Zones: A natural experiment in urban public parks. Health \& Place. 2012;18(1):39-45.

12. Ding D, Gebel K. Built environment, physical activity, and obesity: What have we learned from reviewing the literature? Health \& Place. 2011(in press).

13. Sandercock G, Angus C, Barton J. Physical activity levels of children living in different built environments. Preventive Medicine. 2010;50(4):193-198.

14. Renalds A, Smith TH, Hale PJ. A Systematic Review of Built Environment and Health. Family \& Community Health. 2010;33(1):68-78 10.1097/FCH.1090b1013e3181c1094e1092e1095.

15. Feng J, Glass TA, Curriero FC, Stewart WF, Schwartz BS. The built environment and obesity: A systematic review of the epidemiologic evidence. Health \& Place. 2010;16(2):175-190.

16. Saelens B, Handy S. Built environment correlates of walking: A review. Medicine and Science in Sports and Exercise. 2008;40(7):S550 - 566.

17. Kaczynski AT, Henderson KA. Environmental Correlates of Physical Activity: A Review of Evidence about Parks and Recreation. Leisure Sciences: An Interdisciplinary Journal. 2007;29(4):315 - 354.

18. Van Dyck D, Cerin E, Conway T, et al. Perceived neighborhood environmental attributes associated with adults' transport-related walking and cycling: Findings from the USA, Australia and Belgium. International Journal of Behavioral Nutrition and Physical Activity. 2012;9(1):70.

19. Cerin E, Conway T, Saelens B, Frank L, Sallis J. Cross-validation of the factorial structure of the Neighborhood Environment Walkability Scale (NEWS) and its abbreviated form (NEWS-A). International Journal of Behavioral Nutrition and Physical Activity. 2009;6(1):32.

20. Hipp JA, Adlakha D, Eyler AA, Chang B, Pless R. Emerging Technologies: Webcams and Crowd-Sourcing to Identify Active Transportation. American Journal of Preventive Medicine. 2013;44(1):96-97.

21. Hipp JA, Adlakha D, Eyler A, Pless R. The Use of Webcams and Internet Crowdsourcing to Evaluate Built Environment Change'. Active Living Research. San Diego, CA2013.

22. Kamel Boulos M, Resch B, Crowley D, et al. Crowdsourcing, citizen sensing and sensor web technologies for public and environmental health surveillance and crisis management: trends, OGC standards and application examples. International Journal of Health Geographics. 2011;10(1):67.

23. Ginsberg J, Mohebbi MH, Patel RS, Brammer L, Smolinski MS, Brilliant L. Detecting influenza epidemics using search engine query data. Nature. 2008;457(7232):1012-1014.

24. Mason W, Suri S. Conducting behavioral research on Amazon's Mechanical Turk. Behavior Research Methods. 2012;44(1):1-23.

25. Bohannon J. Social science for pennies. Science. 2011(334):307.

26. Buhrmester M, Kwang T, Gosling SD. Amazon's Mechanical Turk. Perspectives on Psychological Science. January 1, 2011 2011;6(1):3-5. 